\title{
Immunological determination of serum m-AST activity in patients with acute myocardial infarction
}

\author{
MICHITOSHI INOUE, MASATSUGU HORI, YOSHIHIRO NISHIMOTO, \\ SUGAO FUKUI, HIROSHI ABE, HIROSHI WADA, AND TAKAZO MINAMINO
}

From the First Department of Medicine, and the Second Department of Pharmacology, Osaka University, Medical School; and the Sakurabashi Watanabe Hospital

SUMMARY Serum m-AST (mitochondrial isoenzyme of AST) activity in patients with acute myocardial infarction was determined quantitatively by a new immunological technique which is sensitive and easily available. All 31 patients with acute myocardial infarction showed abnormally high levels of serum m-AST (more than $5 \mathrm{KU} / \mathrm{ml}$ ); the mean serum m-AST activity attained its peak $(42.0 \pm$ $4.9 \mathrm{KU} / \mathrm{ml}$ ) on the first day after the onset of infarction 5 hours later than that of serum t-AST (total AST) activity in 15 patients whose peak $\mathrm{m}$ - and t-AST activities were identified clearly. The individual peak $m$-AST activity correlated with the total CK released $(r=0.83, n=15)$, indicating that the release of $\mathrm{m}$-AST also reflects the infarct size. The ratio of serum $\mathrm{m}$-AST/t-AST increased following myocardial infarction and showed the maximal value (average $25.7 \%$ ) on the third to seventh day after onset. This ratio in the patients with acute myocardial infarction was also greater than that in patients with liver disease or with heart failure from causes other than acute myocardial infarction. In the patients who had the additional complication of heart failure and/or cardiogenic shock the ratio was also greater than that in the patients without these hazards. These results indicate that the ratio of serum m-AST/tAST reflects the severicy of the myocardial cellular damage in acute myocardial infarction.

Aspartate aminotransferase ( $\mathrm{L}$ :aspartate:2-oxoglutarate aminotransferase, E.C.2.6.1.1.; AST) consists of two isoenzymes, one associated with the cytoplasmic fraction (s-AST) and the other with mitochondria (m-AST) (Fleisher et al., 1960; Borst and Peeters, 1961; Boyd, 1961; Massarrat and Lang, 1965). Since AST is mainly contained in striated muscle, myocardium, and liver, its serum activity has been found to rise in diseases of these organs (Schmidt et al., 1967; Farmer et al., 1970; Idéo et al., 1971). Though the ratio of serum m-AST activity to total serum AST (t-AST) activity has been reported to represent the severity of cellular damage in liver disease (Schmidt and Schmidt, 1961; Idéo et al., 1972), the clinical significance in myocardial infarction of $\mathrm{m}$-AST and the ratio $\mathrm{m}-\mathrm{AST} / \mathrm{t}-$ AST remains unsettled, probably because the previous methods for the determination of m-AST using electrophoresis or column chromatography were inadequate in sensitivity as well as quantitatively (Fleisher et al., 1960; Boyd, 1961; Bodansky et al., 1966; Idéo et al., 1971).

Received for publication 8 September 1977
Modern medical treatment of acute myocardial infarction, however, attempts to salvage the jeopardised myocardium surrounding the fully infarcted area. Thus, the evaluation of the degree of the cellular damage within the ischaemic myocardium and the assessment of the extent of infarcted area are of great importance.

Recently Wada et al. (1976) described a new immunological technique for the determination of serum m-AST activity which is more sensitive and more easily available than previous methods. Accordingly, in the present study we used this new method to investigate the serial changes of serum $\mathrm{m}$-AST activities and also the ratio of the serum $\mathrm{m}-\mathrm{AST} / \mathrm{t}$-AST in patients with acute myocardial infarction. The results were compared with those in patients with liver disease and with cardiac failure as well as with normal controls.

\section{Subjects}

NORMAL SUBJECTS

Eighty-two healthy subjects (42 men and 40 women, whose ages ranged from 20 to 71 years, average 42 
years) were studied to determine the normal range of serum m-AST activity. In order to match the age range of a control group with that of the patients with acute myocardial infarction, 27 subjects of more than 50 years were also selected; the average age was $56 \cdot 3$ years.

\section{ACUTE MYOCARDIAL INFARCTION}

Serum m-AST, t-AST, and creatine kinase (CK) activities were determined in 31 patients with acute myocardial infarction whose onset of infarction was clearly identified. There were 26 men and 5 women, whose ages ranged from 35 to 76 years (average 61.5 years). None of these patients died within a week of onset of the illness. The diagnosis of myocardial infarction was established by a history of typical chest pain, characteristic electrocardiographic abnormalities, and an increase in serum enzyme activities (CK, lactic dehydrogenase, and $\alpha$-hydroxybutyric dehydrogenase).

In all patients we measured (i) the individual peak levels of serum m-AST and t-AST, (ii) the interval from the onset of symptoms to the peak levels of serum $\mathrm{m}$-AST and $\mathrm{t}-\mathrm{AST}$ activities, and (iii) the serial changes in the ratio $\mathrm{m}-\mathrm{AST} / \mathrm{t}-\mathrm{AST}$. The total $\mathrm{CK}$ released, which represents the infarct size, was also obtained by the method of Sobel et al. (1972) modified by Norris et al. (1975) in 15 patients without cardiogenic shock or severe arrhythmia in the acute phase who survived for more than 7 days.

In order to investigate the relation between serum m-AST levels and the complication of pump failure, the 31 patients were divided into two groups according to the criteria of Killip and Kimball (1968): group 1 consisted of 19 patients (average age 57.6 years) without heart failure, and group 2 of 12 patients (average age 67.2 years) with heart failure and/or cardiogenic shock.

\section{CARDIAC FAILURE}

In order to investigate the contribution of the $\mathrm{m}$-AST released from liver in the patients with heart failure but without muscular necrosis, serum $\mathrm{m}$-AST and t-AST activities were determined in 16 patients (average age 44.5 years) with cardiac failure caused by valvular disease (11 patients) or congestive cardiomyopathy (5 patients).

\section{LIVER DISEASE}

The ratio of $\mathrm{m}$-AST/t-AST in 23 patients with acute or chronic hepatitis, not including fulminant hepatitis (average age 40.3 years), and 12 patients with liver cirrhosis (average age 53.3 years) were compared with the ratios in patients with acute myocardial infarction.

\section{Methods}

A new method for the determination of serum $\mathrm{m}$-AST activity is based on the difference in the immunological properties of the isoenzymes. Serum m-AST activity was assessed as the total residual AST activity after complete removal of s-AST (cytoplasmic fraction) with the immunoadsorbent, red blood cells sensitised with anti-s-AST antibody.

\section{(i) PREPARATION OF IMMUNOADSORBENT}

Anti-s-AST antibodies were prepared in rabbits by injecting the purified human s-AST with Freund's complete adjuvant. Purification of s-AST was performed by the method of Morino et al. (1963). The IgG fraction was purified by the modified method of Petersen et al. (1961) from the anti-sera; its anti-sAST titre is higher than 1:10 000. IgG fraction was mixed with 2 volumes of phosphate buffer solution containing 50 per cent sheep red cells. One volume of 5 per cent glutaraldehyde solution was added to this mixture with stirring. Red cells precipitated centrifugation were thoroughly washed with phosphate buffer solution and suspended in phosphate buffer solution so as to give a concentration of 20 per cent. This suspension was used as the immuno-adsorbent of s-AST.

\section{(ii) ASSAY OF m-AST ACTIVITY}

To determine the serum m-AST activity, s-AST was removed from the test serum with the immunoadsorbent described above. The immunoadsorbent ( $1 \mathrm{ml}$ ) was suspended in $5 \mathrm{ml}$ of $0.15 \mathrm{M}$ phosphate buffer solution ( $\mathrm{pH} 7 \cdot 2$ ). The mixture was centrifuged at $1500 \mathrm{~g}$ for 3 minutes and the precipitate was mixed thoroughly with $0.5 \mathrm{ml}$ of the serum specimen. The mixture was allowed to stand at room temperature for about 5 minutes, with occasional stirring. The immunoadsorbent was completely removed by centrifugation at $1500 \mathrm{~g}$ for 5 minutes and $0.2 \mathrm{mg} / \mathrm{ml}$ of the supernatant solution was used to assay the m-AST activity. M-AST and t-AST activity was measured by the spectrophotometric method coupled with malic dehydrogenase and expressed in Karmen units.

\section{(iii) RELIABILITY OF METHOD}

In order to evaluate the reliability of this method we prepared the standard AST sera containing known amounts of $\mathrm{m}$ - and s-AST with various ratios of these isoenzymes (see Table 1). The standard sera were prepared from crystallised $\mathrm{m}$ - and s-AST obtained from the pig heart by the method of Morino et al. (1977); the respective activities of these isoenzymes can be determined by the spectrophotometric technique as described above. Measure- 
Table 1 Test of accuracy of $m-A S T$ determination by immunoadsorbent method. Standard sera were prepared from crystallised $m-A S T$ and $s-A S T$ of pig heart

\begin{tabular}{lrrrrrr}
\hline $\begin{array}{l}\text { AST standard } \\
\text { serum }\end{array}$ & s-AST & 200 & 200 & 200 & 200 & 200 \\
\cline { 2 - 7 } & m-AST & 10 & 20 & 40 & 80 & 160 \\
\hline $\begin{array}{l}\text { Measured activity } \\
\text { of m-AST }\end{array}$ & 9 & 22 & 40 & 82 & 163 \\
\hline
\end{tabular}

Activity is expressed in $\mathrm{KU} / \mathrm{ml}$.

ment of m-AST activity of these standard sera by our new method revealed the excellent reliability of the method and the electrophoresis of the serum from which the s-AST is removed with immunoadsorbent showed only a band which was completely identical with a band produced by crystallised $\mathrm{m}-\mathrm{AST}$, indicating that s-AST activity can be assessed as the difference between the activities of $\mathrm{t}$ - and $\mathrm{m}$-AST for routine work (Table 1).

\section{Results}

(1) NORMAL VALUE OF SERUM M-AST ACTIVITY The mean serum m-AST activity determined in 82 healthy subjects was $1.0 \mathrm{KU} / \mathrm{ml}$, ranging from 0 to $6 \mathrm{KU} / \mathrm{ml}$. The mean value of serum $\mathrm{m}-\mathrm{AST}$ in 17 patients more than 50 years old was $1.5 \mathrm{KU} / \mathrm{ml}$ (0 to $5 \mathrm{KU} / \mathrm{ml}$ ).

To evaluate the reproducibility of our method, we determined in triplicate the m-AST activity of each of 15 serum samples from patients with myocardial infarction. The maximum error in determination

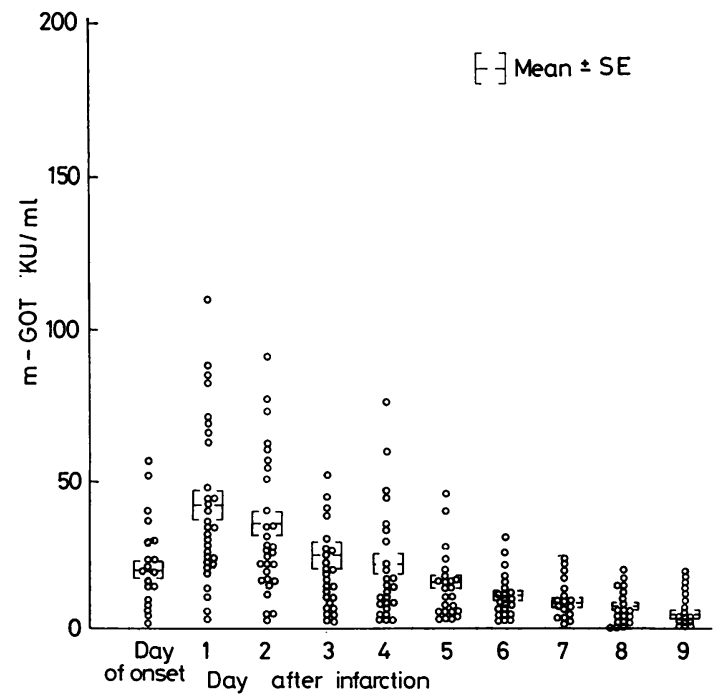

Fig. 1 Daily serum $m$-AST activities in 31 patients with acute myocardial infarction. was 8.4 per cent (mean error was $6.4 \%$ ), indicating a good reproducibility of the method.

\section{(2) SERUM M-AST ACTIVITY IN PATIENTS WITH} ACUTE MYOCARDIAL INFARCTION

(i) Serial changes of serum $m-A S T$ activities

Fig. 1 shows the serial changes of the mean serum $\mathrm{m}$-AST activities in 31 patients with acute myocardial infarction. On the day of onset the mean $\mathrm{m}$ AST activity was raised $(20.2 \pm 2.9 \mathrm{KU} / \mathrm{ml})$ and increased to the maximum $(42.0 \pm 4.9 \mathrm{KU} / \mathrm{ml})$ on the first day after infarction, decreasing gradually thereafter to the normal level $(<5 \mathrm{KU} / \mathrm{ml}$ ) on the ninth day of infarction. When more than two determinations were performed in a day, a value obtained early in the morning was illustrated as a representative value of an individual for that day after onset. The mean t-AST activity also showed a peak value $(280.5 \pm 38.2 \mathrm{KU} / \mathrm{ml})$ on the first day after onset of infarction (see Fig. 2) but returned to normal on the seventh day after onset. In 15 patients whose serum $\mathrm{m}$-AST and $\mathrm{t}$-AST activities were determined every 4 hours within the first 24 hours and thereafter every 6 hours until CK activity returned to normal, the mean peak m-AST activity $(65.7 \pm$ $9 \cdot 8 \mathrm{KU} / \mathrm{ml}$ ) was obtained on average at $34.6 \pm 3.2$ hours after the onset of infarction, returning to

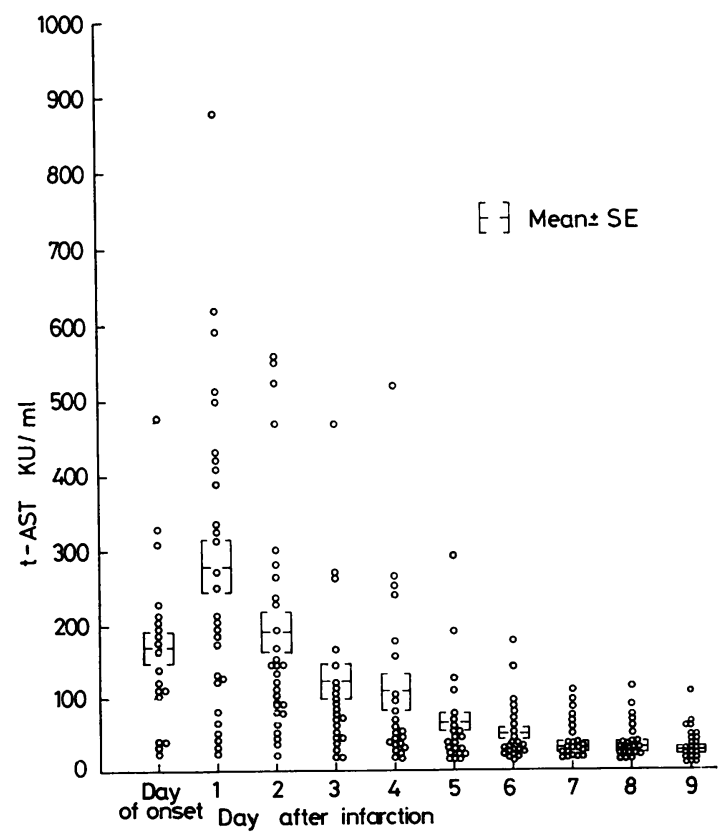

Fig. 2 Daily serum $t$-AST activities in 31 patients with acute myocardial infarction. 
Table 2 Ratio $m-A S T / t-A S T$ after onset of infarction in groups 1 (without heart failure) and 2 (with heart failure and/or cardiogenic shock (mean $\pm S E(\%))$

\begin{tabular}{|c|c|c|c|c|c|c|c|c|c|}
\hline \multirow[b]{2}{*}{ Day of onset } & \multicolumn{9}{|c|}{ Day after onset } \\
\hline & 1st & $2 n d$ & $3 r d$ & $4 t h$ & $5 t h$ & $6 t h$ & $7 t h$ & $8 t h$ & $9 t h$ \\
\hline
\end{tabular}

Group $1 \quad 14 \cdot 5 \pm 2 \cdot 1 \quad 17 \cdot 5 \pm 2 \cdot 0 \quad 17 \cdot 6 \pm 2 \cdot 1 \quad 21 \cdot 3 \pm 2 \cdot 2 \quad 21 \cdot 8 \pm 2 \cdot 123 \cdot 6 \pm 2 \cdot 2 \quad 25 \cdot 3 \pm 2 \cdot 0 \quad 26 \cdot 4 \pm 2 \cdot 2 \quad 19 \cdot 0 \pm 4 \cdot 1 \quad 20 \cdot 5 \pm 2 \cdot 6$

Group $220.3 \pm 4.4 \quad 16.5 \pm 3.020 .3 \pm 4.033 .6 \pm 5.126 .3 \pm 3.725 .4 \pm 4.023 .1 \pm 1.523 .0 \pm 4.524 .4 \pm 6.032 .5 \pm 10.5$

Total $16.8 \pm 2 \cdot 1 \quad 17 \cdot 1 \pm 1.618 .0 \pm 1 \cdot 725.7 \pm 2.523 .7 \pm 2.023 .8 \pm 1.924 .6 \pm 1.424 .3 \pm 2.921 .5 \pm 3.323 .1 \pm 3.4$

$\star P<0.01$.

normal on the ninth day after the onset, while the mean peak t-AST was $420 \cdot 7 \pm 50.5 \mathrm{KU} / \mathrm{ml}$ which was obtained on average $29.4 \pm 2.9$ hours after the onset (about 5 hours earlier than that of m-AST), returned to normal on the seventh day of infarction.

The mean ratio of the individual serum $\mathrm{m}$-AST to $\mathrm{t}$-AST activity (m-AST/t-AST) increased gradually after infarction reaching a maximum $(25.7 \pm 2.5 \%)$ on the third day after onset (Table 2$)$. Though individual values of this ratio showed a wide range at each study interval, the mean of the ratios $\mathrm{m}$-AST/t-AST in 12 patients in group 2 (with heart failure and/or cardiogenic shock) was higher than that in 19 patients in group 1 (without heart failure) at every study interval except the first, sixth, and seventh day after onset (see Table 2). On the third day after infarction the maximal mean $\mathrm{m}$-AST/t-AST was obtained. This ratio in group 2 was $33.6 \pm 5 \cdot 1$ per cent which was significantly greater than that in group $1(21.3 \pm 2 \cdot 2 \%, \mathrm{P}<$ 0.01 ).

(ii) Relation between peak value of serum $m-A S T$ activity and total $C K$ released

In 15 out of 31 patients serum $\mathrm{m}-\mathrm{AST}$ and $\mathrm{CK}$ activities were determined every 4 hours within the first 24 hours and thereafter every 6 hours until $\mathrm{CK}$ activity returned to normal, and the relation between the peak serum m-AST activity and the total CK released (which directly reflects infarct size) was investigated. The individual peak m-AST activities (Fig. 3) showed a close correlation with the total $\mathrm{CK}$ released $(\mathrm{r}=0.83, \mathrm{n}=15)$, indicating that the peak m-AST activity also reflects infarct size.

\section{(3) SERUM M-AST ACTIVITY IN PATIENTS}

WITH HEART FAILURE

The average serum $\mathrm{m}$-AST and t-AST activities were $19 \cdot 3 \pm 6 \cdot 0(3-102) \mathrm{KU} / \mathrm{ml}$, and $164 \cdot 1 \pm 51 \cdot 0$ $(37-830) \mathrm{KU} / \mathrm{ml}$, respectively, in 16 patients with heart failure caused by valvular heart disease or congestive cardiomyopathy but without infarction. The ratio $\mathrm{m}$-AST/t-AST averaged $12 \cdot 2 \pm 1 \cdot 0$ per

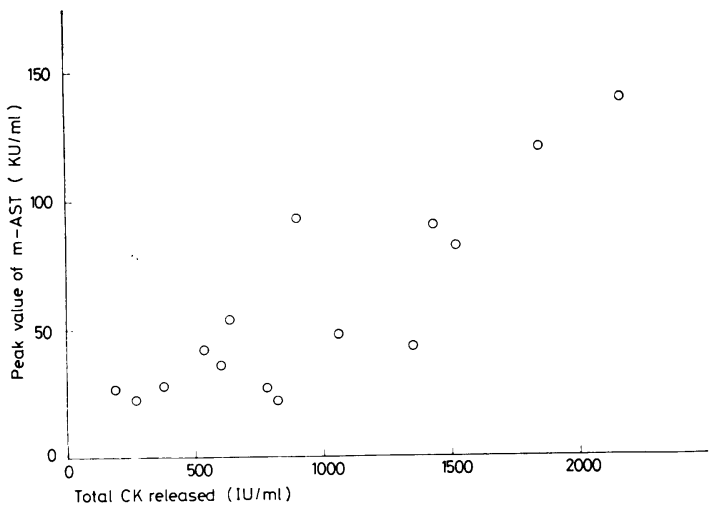

Fig. 3 Relation between the peak $m-A S T$ activity and the total $C K$ released.

cent $(6 \cdot 0-21 \cdot 7 \%)$ which was substantially less than that of the patients with acute myocardial infarction - statistically significant from the third to seventh day after onset $(P<0.01)$.

\section{(4) SERUM M-AST ACTIVITY IN PATIENTS} WITH LIVER DISEASE

The mean serum m-AST activity was $8.9 \pm 2.0$ $(0-70) \mathrm{KU} / \mathrm{ml}$ in 23 patients with acute or chronic hepatitis, while the mean serum t-AST activity was $70.5 \pm 11.3(11-246) \mathrm{KU} / \mathrm{ml}$. In 12 patients with liver cirrhosis the mean m-AST activity $(17 \cdot 3 \pm$ $5.4 \mathrm{KU} / \mathrm{ml}$ ) was slightly greater than that of the patients with hepatitis.

The mean values of the ratios m-AST/t-AST in the patients with hepatitis and liver cirrhosis were $12.7 \pm 1.8$ per cent and $11.3 \pm 2.0$ per cent, respectively, both being significantly less than the values obtained from third to seventh day after onset in acute myocardial infarction $(P<0.01)$.

\section{Discussion}

In 1961 Borst and Peeters (1961) reported that aspartate transaminase has two isoenzymes corres- 
ponding to cytoplasmic and mitochondrial fractions (s-AST and $\mathrm{m}$-AST). In patients with liver disease, the detection of serum m-AST activity has been considered to reflect severe cellular damage (Schmidt and Schmidt, 1963). The clinical significance of serum m-AST activity in acute myocardial infarction, however, was unknown. This is partly because the previous methods using electrophoresis or column chromatography allow only semiquantitative determination with inadequate sensitivity.

In the present study we assessed serum m-AST activities quantitatively in patients with acute myocardial infarction by an immunological method with high sensitivity which was recently reported by Wada and his associates (1976). All patients in our series showed abnormal high m-AST activity (18 to $132 \mathrm{KU} / \mathrm{ml}$ ). Their peak values correlated with the total CK released, which has been shown to be related to infarct size (Sobel et al., 1972; Inoue et al., 1977). This finding strongly suggests that in patients with acute myocardial infarction m-AST activity is derived from the myocardium and hepatic m-AST contributes only minimally to serum m-AST activity. Myocardial and hepatic m-AST are immunochemically identical (Morino et al., 1964).

Our results also showed that the peak values of n-AST were obtained on the average 5 hours after the peak of t-AST activity. These results agree with the report by Murros et al. (1973) that serum m-AST activity determined by electrophoresis increased to above normal in 23 of 24 patients with acute myocardial infarction and that its peak level was usually obtained later than that of t-AST, indicating the delayed release of $\mathrm{m}$-AST into the circulation.

Although Calva et al. (1974) also described this delay in the peak time of m-AST activity in coronary occlusion in 5 of 10 dogs, they could not detect serum m-AST activity in two infarcted dogs. In contrast to this and other previous reports (Fleisher and Wakim, 1961; Bodansky et al., 1966; Murros et al., 1973), all the patients with acute myocardial infarction in our study had abnormally high m-AST activities. This difference suggests that our immunological method, using the sensitised erythrocytes of sheep to eliminate the antigen-antibody complex of s-AST, has higher sensitivity than the previous technique. Indeed we detected serum m-AST activity in 31 of 35 patients with liver disease, though Murros et al. (1973) could not detect mAST activity in the serum of their patients with liver disease whose serum t-AST was less than $100 \mathrm{KU} / \mathrm{ml}$, even with the immunological technique.

The improvement in sensitivity for determination of m-AST activity, however, could result in a higher value for the ratio m-AST/t-AST. In our study the mean value of the individual maximal $\mathrm{m}-\mathrm{AST} / \mathrm{t}-$ AST was $30.2 \pm 1.7$ per cent (12 to 64$)$ and this value is significantly greater than those in the patients with liver disease previously reported (Farmer et al., 1970; Idéo et al., 1971). In the present study, the mean ratio of m-AST/t-AST in 35 patients with liver disease was $12.2 \pm 1.9$ per cent and was similar to the previous reported results (Fleisher and Wakim, 1961). Accordingly our results strongly suggest that the ratio of $m-A S T / t-$ AST in acute myocardial infarction is larger than it is in liver disease and confirm the work of Farmer et al. (1970).

There are two possible reasons for this difference in the ratio m-AST/t-AST between acute myocardial infarction and liver disease. The first possibility is that the ratio m-AST/t-AST of the myocardial tissue is greater than that of liver, and this difference is reflected in the larger ratio of serum m-AST/tAST in patients with acute myocardial infarction. Bodansky et al. (1966) reported that the ratios of $\mathrm{m}$-AST/t-AST in myocardial tissue and in liver tissue were 68 and 49 per cent, respectively. Recently, however, one of the authors (H.W.) also determined these ratios in the myocardium and liver by our method, and showed that the liver contained a higher percentage of m-AST $(71.0 \%)$ than the myocardium (64.0\%, unpublished data). This finding made it difficult for us to accept the first possibility that the higher ratio m-AST/t-AST in myocardial infarction was the result of the higher content ratio of the myocardium.

The second possibility is that the larger ratio of serum $\mathrm{m}$-AST/t-AST reflects severe cellular insult to the mitochondria. Calva et al. (1974) reported that higher levels of m-AST were observed when the necrosis was extensive and transmural, and in dogs with extensive infarction the ratio of serum $\mathrm{m}$-AST/t-AST was more than 25 per cent. In our cases also the serum m-AST/t-AST was smaller in group 1 (without heart failure). This result was incompatible with the study of Calva et al. (1974) which showed the mean total CK released was significantly greater in group 2 than in group 1. These results strongly suggest that the serum $\mathrm{m}$-AST/t-AST reflects the degree of the myocardial tissue damage in acute myocardial infarction. The reduction of the ratio of serum $\mathrm{m}-\mathrm{AST} / \mathrm{t}-\mathrm{AST}$ (the mean maximal ratio; $30.2 \%$ ) from that of myocardial m-AST/t-AST $(64.0 \%)$ might be the result of the higher lability of m-AST than s-AST (cytoplasmic AST) as suggested by the previous studies of Fleisher and Wakim (1961).

However, the substantially large ratio of $\mathrm{m}$-AST/t-AST was obtained on the third to seventh 
day after onset, a few days after the peak of m-AST, which indicates that there is a gradual release of m-AST from the damaged myocardium several days after infarction since the disappearance rate of $\mathrm{m}$-AST in serum was reported to be more rapid than that of s-AST (Fleisher and Wakim, 1961). Though our results indicate that the $\mathrm{m}-\mathrm{AST} / \mathrm{t}-\mathrm{AST}$ could be an index of severity of infarction, further investigations are needed to elucidate the quantitative relation between the release of $\mathrm{m}-\mathrm{AST}$ and the degree of myocardial damage.

Preparation of antibody sensitised sheep blood cells was kindly supplied by Eiken Chemical Co., Ltd. We are also grateful to Dr Frank A. Brown for assistance in preparation of this manuscript.

\section{References}

Bodansky, O, Schwarz, M. K., and Nisselbaum, J. S. (1966). Isozymes of aspartate aminotransferase in tissue and blood of man. Advances in Enzyme Regulation, 4, 299-315.

Borst, P., and Peeters, E. M. (1961). The intracellular localization of glutamate oxaloacetate transaminase in heart. Biochimica et Biophysica Acta, 54, 188-189.

Boyd, J. W. (1961). The intracellular distribution, latency and electrophoretic mobility of L-glutamate-oxalacetic transaminase from rat liver. Biochemical fournal, 81, 434-441.

Calva, E., Aoki, K., Delgadillo, J., López-Soriano, F., and Christlieb, I. (1974). Immunological identification in plasma of mitochondrial and cytoplasmic aspartate transaminase isoenzymes during experimental myocardial infarction. American Heart fournal, 87, 614-618.

Farmer, S. N., Nanji, A. M., and Boyde, T. R. C. (1970). Mitochondrial aspartate transaminase. Lancet, 1, 475.

Fleisher, G. A., Potter, C. S., and Wakim, K. G. (1960). Separation of 2 glutamic-oxalacetic transaminases by paper electrophoresis. Proceedings of the Society for Experimental Biology and Medicine, 103, 229-231.

Fleisher, G. A., and Wakim, K. G. (1961). Presence of two glutamic-oxaloacetic transaminases in serum of dogs following acute injury of the liver. Proceedings of the Society for Experimental Biology and Medicine, 106, 283-286.

Idéo, G., de Franchis, R., Bellobuono, A., Sforzini, S., and Dioguardi, N. (1972). Serum cytosolic/mitochondrial enzyme ratio: a tool for the estimation of the severity of acute hepatitis. Zeitschrift für klinische Chemie und klinische Biochemie, 10, 74-76.

Idéo, G., de Franchis, R., Bellobuono, A., and Tornaghi, G. (1971). Aspartate aminotransferase isoenzymes in human serum in various liver diseases. Enzyme, 12, 529-536.

Inoue, M., Hori, M., Fukui, S., Abe, H., Minamino, T., Kodama, K., and Ohgitani, N. (1977). Evaluation of evolution of myocardial infarction by serial determination of serum creatine phosphokinase activity. British Heart fournal, 39, 485-492.
Killip, T., and Kimball, J. T. (1968). Survey of the coronary care unit: concept and results. Progress in Cardiovascular Diseases, 11, 45-52.

Massarrat, S., and Lang, N. (1965). Immunologie und Enzymkinetik der Glutamat-Oxalacetat-Transaminase (GOT) und der Glutamat-Pyruvat-Transaminase (GPT). III. Mittellung. Untersuchungen zur Immunhemmung der Transaminasen im Serum von Leberkranken und von Patienten nach Herzinfarkt (in German). Klinische Wochenschrift, 43, 602-606.

Morino, Y., Itoh, H., and Wada, H. (1963). Crystallization of 2-oxoglutamate L-aspartate transaminases from mitochondrial and soluble fractions of beef liver. Biochemical and Biophysical Research Communications, 13, 348-352.

Morino, Y., Kagamiyama, H., and Wada, H. (1964). Immunochemical distinction between glutamic-oxalacetic transaminases from the soluble and mitochondrial fractions of mammalian tissues. Fournal of Biochemical Chemistry, 239, PC943-PC944.

Morino, Y., Tanase, S., Watanabe, T., Kagamiyama, H., and Wada, H. (1977). Large scale preparation of cytosolic and mitochondrial aspartate aminotransferases from pig heart. Fournal of Biochemistry, 82, 847-852.

Murros, J., Konttinen, A., and Somer, H. (1973). Mitochondrial aspartate aminotransferase in myocardial infarction. Clinica Chimica Acta, 48, 241-242.

Norris, R. M., Whitlock, R. M. L., Barratt-Boyes, C., and Small, C. W. (1975). Clinical measurement of myocardial infarct size; modification of a method for the estimation of total creatine phosphokinase release after myocardial $\infty$ infarction. Circulation, 51, 614-620.

Peterson, E. A., Wyckoff, M. M., and Sober, H. A. (1961). Gradient chromatography of human serum proteins and its application to the examination of 'albumin' and 'globulin' obtained by ammonium sulfate fractionation. Archives of Biochemistry and Biophysics, 93, 428-434.

Schmidt, E., and Schmidt, F. W. (1961). Physiologische Grundlagen der Leber-Enzymdiagnostik (in German). Bibliotheca Gastroenterologica, 4, 15-34.

Schmidt, E., and Schmidt, F. W. (1963). Enzym-bestimmungen im Serum bei Leber-Erkrankungen. Enzymologia Biologica et Clinica, 3, 1-52.

Schmidt, E., Schmidt, W., and Otto, P. (1967). Isoenzymes of malic dehydrogenase, glutamic oxaloacetic transaminase and lactic dehydrogenase in serum in disease of the liver. Clinica Chimica Acta, 15, 283-289.

Sobel, B. E., Bresnahan, G. F., Shell, W. E., and Yoder, R. D. (1972). Estimation of infarct size in man and its relation to prognosis. Circulation, 46, 640-648.

Wada, H., Kagamiyama, H., Teranishi, H., Ohyanagi, H., Shirakawa, M., Mitsuno, T., Fuse, K., and Sawada, Y. 은 (1976). A simple immunological method for differential determination of serum GOT-isoenzymes and its clinical application. In Proceedings of 10th International Congress of Biochemistry, 13-1-213, Hamburg, 25-31 fuly, 1976.

Requests for reprints to Dr Michitoshi Inoue, First Department of Medicine, Osaka University Medical School, 1-1-50 Fukushima, Fukushima-ku, Osaka 553, Japan. 